\title{
Transparency and Context: the Design Process of Hans Verplancke
}

\author{
Fátima Pombo $^{1^{*}}$, Hans Verplancke ${ }^{2}$, and Hilde Heynen ${ }^{3}$ \\ ${ }^{1}$ Guest Professor of Department of Architecture, Urbanism and Planning, University of Leuven, Belgium. E-mail: \\ fatima.teixeirapombo@asro.kuleuven.be, *corresponding author. \\ ${ }^{2}$ Professor of Department of Architecture, Urbanism and Planning, University of Leuven, Belgium \\ ${ }^{3}$ Full Professor and Head of Department of Architecture, Urbanism and Planning, University of Leuven, Belgium
}

doi:10.5618/arch.2012.v1.n2.7 || Received: 16-06-2012, Accepted: 17-08-2012, Available online: 21-08-2012

\begin{abstract}
When designing his or her own house the architect enjoys a unique type of freedom because there is no previous 'protocol' agreed between architect and client. The paper discusses the design process of the Flemish architect Hans Verplancke regarding the two houses he designed for himself and his family. The different contexts of the two houses stimulated a rather diverse methodological approach to the creative process. For the first house (a reconversion project), his experience as a painter provided an important input, whereas for the second one (a project from scratch) it was rather its conception as a sculptured mass which was paramount. The different moments and specificities of the design process are intertwined with a conception of dwelling space as a multilayered vital reference for its inhabitants. The differences between the two projects recall Colin Rowe's and Robert Slutzky's interpretation of different forms of transparency. The first project is closer to the definition of 'literal transparency' providing clearness in the definition of spaces and a visibility without interruptions between exterior and interior. The second one performs the definition of 'phenomenal transparency', creating ambiguity around the perceptive experience of outside and inside and involving the inhabitant as an active partner of the sensorial metamorphosis. The article concludes that the context provided in both cases a decisive impetus to unfold the design process in a way that resulted in quite important differences between the two works.
\end{abstract}

Keywords: context; literal transparency; phenomenal transparency; design process; interpretation

\section{Introduction}

When an architect designs his or her own house, it seems as if the design process takes precedence over programmatic and other considerations that are usually brought in by the client. Being one's own client indeed makes up for a situation in which the degree of freedom seems far above the one that architects enjoy when working for specific other users. In the oeuvre of Hans Verplancke, a Flemish architect who is one of the partners in the office HASA (the other is Sarah Flebus), the two houses he designed for himself and his family thus stand out as being particularly revealing for his design process.

The first house (2000) was a reconversion project, in which an existing modest house near a railway underwent significant changes, inspired by Verplancke's paintings [1]. The second house (2010), built for a growing family in a semi-rural, residential neighbourhood, was designed from scratch. In both houses, we argue, the design process engaged a certain form of transparency, which in each case can be seen as crucial for the set-up of the overall design. These forms of transparency were very different, however, because they relied upon different sensibilities, different tactics and different contextual elements. The transparency that is characteristic for the first house comes very close to what Colin Rowe and Robert Slutzky termed 'literal transparency', whereas the one in the second house would rather be comparable to what they described as 'phenomenal transparency'.

2. Literal and phenomenal transparency in Architecture

Transparency has long been hailed as one of the characteristics of modern architecture [2]. In their essay entitled 'Transparency: literal and phenomenal', Colin 
Rowe and Robert Slutzky however claim that architecture's transparency is quite different from the one observed in painting and necessitates a thorough analysis [3]. They start their argument by differentiating between 'literal' and 'phenomenal' transparency in painting - the first established by the painterly representation of transparent surfaces which allow one to also see what is supposedly beyond these surfaces; the second a more elaborated feature of paintings which suggest a complex interaction of seemingly transparent surfaces whereas this interaction never adds up to a fully comprehensible and consistent 2-D representation of a 3 -D reality. Whereas literal transparency corresponds to a possible and logical spatiality, phenomenal transparency suggests and evokes such a spatiality that, however, can never be described in a non-ambiguous and consistent way, because its representation is thoroughly ambiguous.

Rowe and Slutzky go on to extend this argument to architecture, which leads them to defend ambiguity in architecture, because this ambiguity enriches architectural works by allowing diverse interpretations. For them, Gropius's Bauhaus provides an example of 'literal transparency', because its material qualities are such that, at certain points, one can see through the building but this quality never raises doubt as to what exactly one is seeing: one can see the interior from the exterior, and sometimes even perceive an exterior space around the corner through an interior space, but the overall constellation of spaces is quite clear throughout.

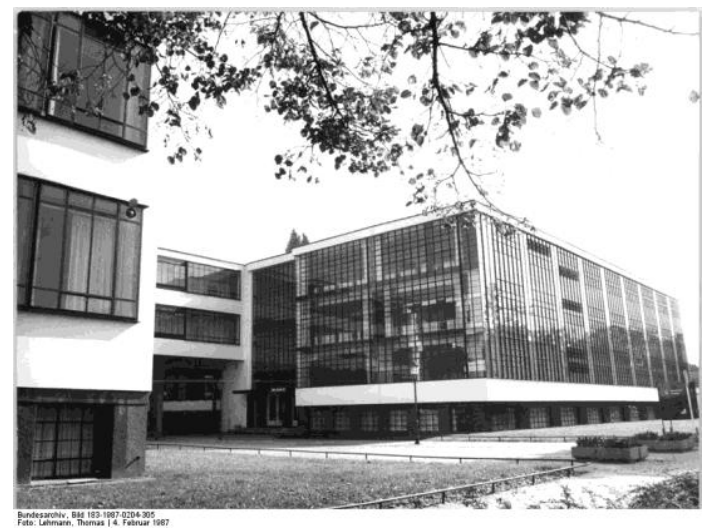

Fig. 1. Bauhaus, Dessau, Walter Gropius, 1925-26.
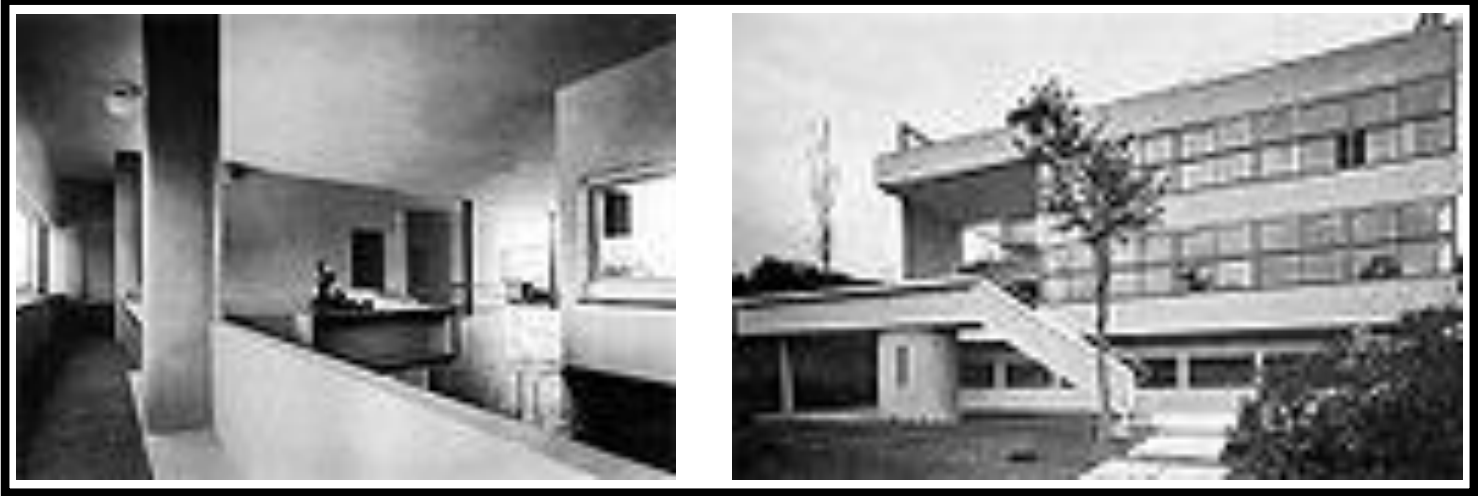

Fig. 2.1. Villa Stein, Garches, Le Corbusier, 1927 (left); Fig. 2.2. Villa Stein, Garches, Le Corbusier, 1927 (right). Gallery and living room, $1^{\text {st }}$ floor

The Villa Stein at Garches from Le Corbusier, on the other hand, displays a rather phenomenal transparency according to them. For Gropius the transparency effect was displayed by conceiving a wall surface in glass to make the inner structure of the building visible from outside. The transparency of Corbusier's building is to be found in a layered concept of visibility. There is not a line of light crossing a glass wall, but a movement of light which occupies the open spaces immediately behind the wall: 'there lies a narrow slot of space (...) there lies a plane of which the ground floor, the freestanding walls and the inner reveals of the doors all form a part' [4]. Therefore, the transparency created by
Le Corbusier is more complex and integrated in the building as a volume. The planes composing this volume are fragmentary. At Garches, the horizontal windows take part in a volume composed of solid vertical surfaces, a frame which caries the cantilevers above. The windows are more than an interaction between inside and outside space. The planes of the façade can here be seen to effect a profound modification of the deep extension of the internal space.

By concluding Rowe and Slutzky state that 'in plan, the Bauhaus reveals a succession of spaces but scarcely a contradiction of spatial dimensions' [5], i.e. the spatial stratification doesn't invite to the possibilities of 
ambiguity. The difference between literal and phenomenal transparency between the two architects is even clearer by comparing the Bauhaus building and Le Corbusier's League of Nations (project of 1927). In The League of Nations the conception and invention of space through 'corners and angles as the indices of spatial dimension' [6] and with the Le Corbusier's planes as 'knives for the apportionate slicing of space' [7] unfolds a perception of transparency that it's not the Bauhaus' plane glazing glass or translucence effect. Le Corbusier designs intersecting spaces which suggest multiple spatial organizations within the building as a whole.

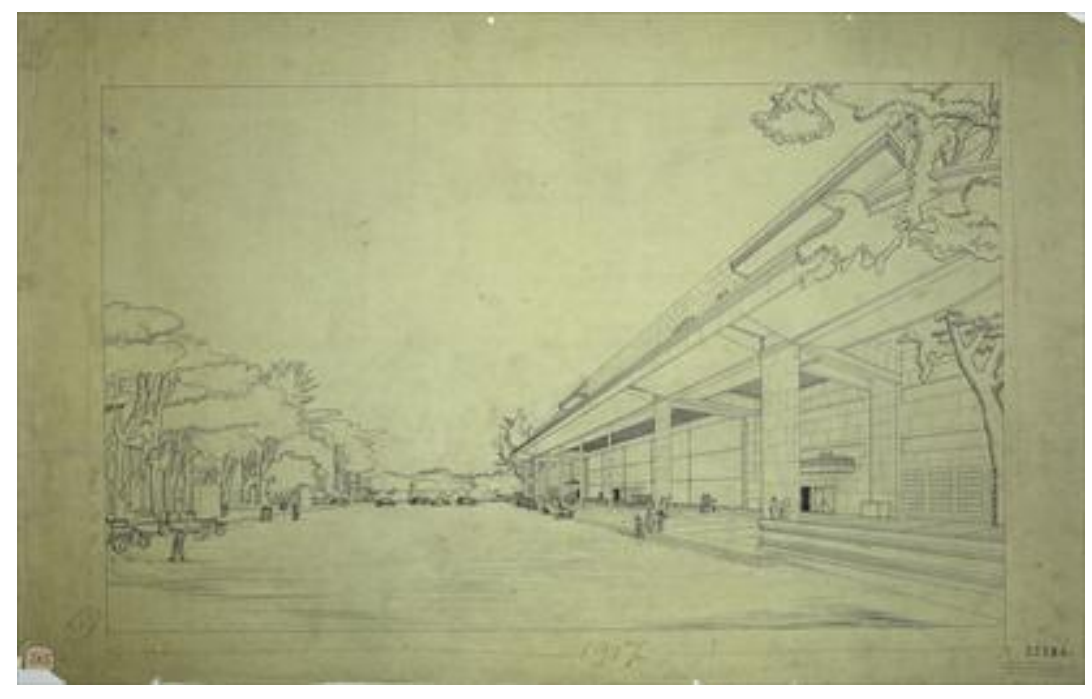

Fig. 3. palace of League of Nations, Le Corbusier, project 1927.

\section{Context generating transparency}

Rowe and Slutzky argued in 1963 that 'simultaneity, interpenetration, superimposition, ambivalence, spacetime, transparency (...) are, we believe, the specific formal characteristics of contemporary architecture' [8]. Sixty years later, the same terms can still be used to unravel some of the intricacies of contemporary design. When designing his houses, Hans Verplancke did not explicitly think about literal and phenomenal transparency - he rather based his designs on considerations of context and from that reference on, dealt differently with the two buildings. However, the result of both projects displayed as consequence two different types of transparency: in the first house literal transparency and in the second house phenomenal transparency.

3.1 First house. Ten years ago Hans Verplancke wanted to buy his own place to live. He wasn't looking for a project of his own; he wanted a house with a history, a house only asking for white painting and furniture. No intervention as "architect" should be needed because he feared to be stitched on that first "own house".
After years of searching, he finally bought a house he could afford, not the one he had in mind, not the one ready for immediate take-in. "The house nearby the railway", as he used to call it, was a typical "row house", with a plan one can draw without even entering the house. (Fig. 4)

3.1.1 Row house. The basic structure of such houses of the beginning of the $20^{\text {th }}$ century is mostly the same.

1. In plan they are divided in a narrow and a wide nave. The narrow nave contains the entrance and the staircase, the wide nave contains the living spaces on the different levels. The attic, the only place where one can feel the full house's width, doesn't take part in the effective living space; it is just storage-room.

2. Behind the basic volume you find an annex containing kitchen, bathroom and storage, on one or two levels.

3. Those houses are built with a strong orientation towards the street. Relations, both physical and visual between the living spaces and the deep and narrow gardens, are rare or limited. 

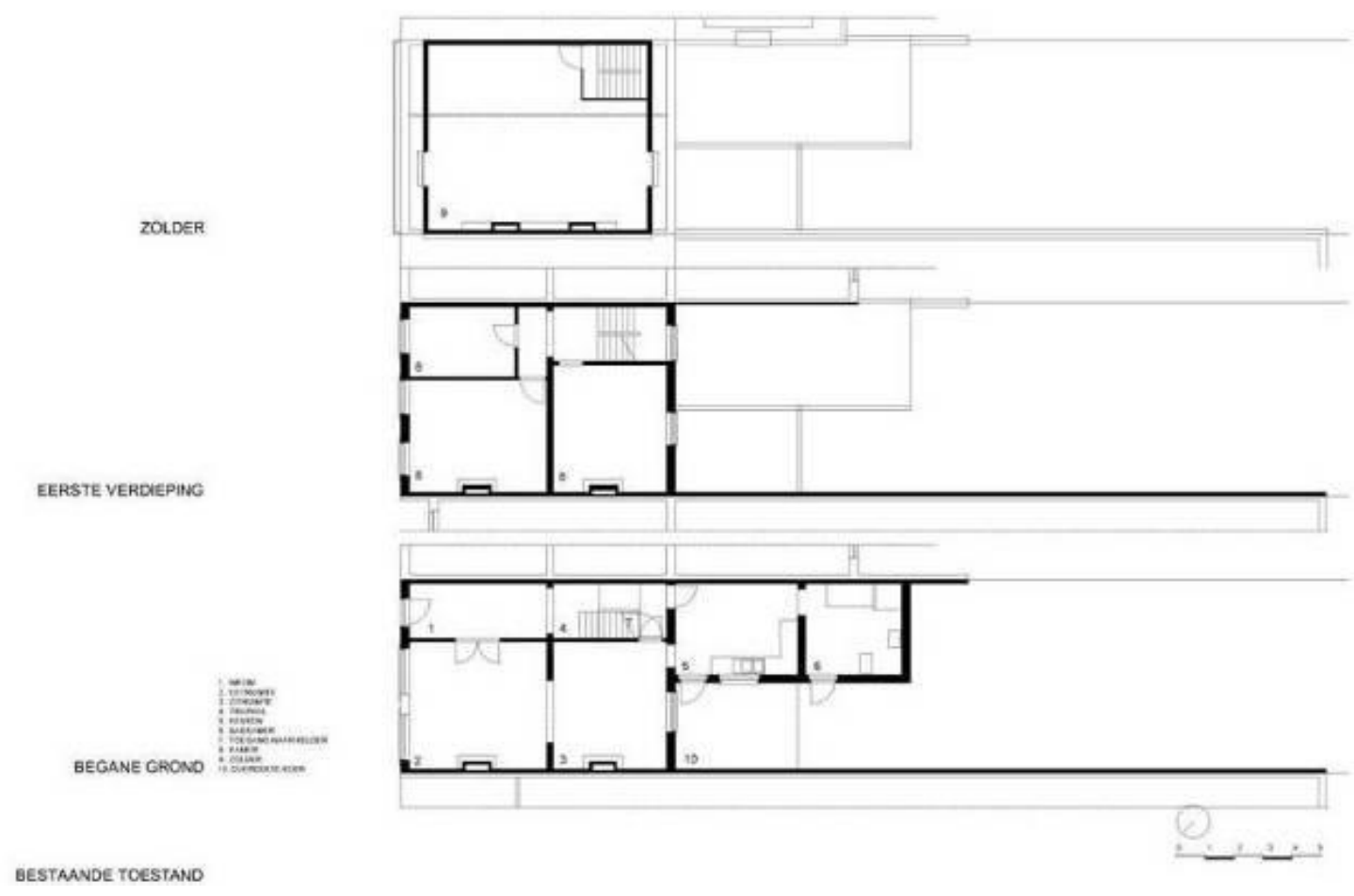

Fig. 4. existing situation.

Depending on the wealth of the original owner, the interior is decorated with paneling, moulding, multicolored tiling, handcraft elements. This particular 'house at the railway' however had lost that glory. The successive owners did some "renovations", all of them resulted in a loss of the authentic, interior atmosphere of the house itself. None of these interventions made it, in terms of space, a better place to live.

The white painting, as mentioned before, wouldn't solve the problem. Verplancke looked to the house from a different point of view, just by questioning the possibilities of the existing house in relation to the environment. The context in which this house was implanted created more potential than the same type of house in an urban context, namely the external conditions of the building location and the conditions of the building block itself. (Fig. 5)

A. External condition:
The location of the building in front of one of the busiest railroad connections in Flanders, for transporting passengers in daytime and goods during the night. In fact, a ringing bell each five minutes, followed by a train and wagons stuffed with trees, cars or containers, put the house in a position of "trembling";

The new industrial park in the adjacent village caused a large increase in freight traffic on the main road. Reuse of the formal factory at the other side of the railway as warehouse and small-business-offices, caused supplementary traffic of people.

\section{B. Conditions of the building block}

This block was wider and deeper than building blocks in urban context. The presence of a small road in the middle of it, giving access to the backside of the gardens, was a great asset. This became a major element in the re-thinking of the typology of the existing house into that changed environment. (Fig. 6) 


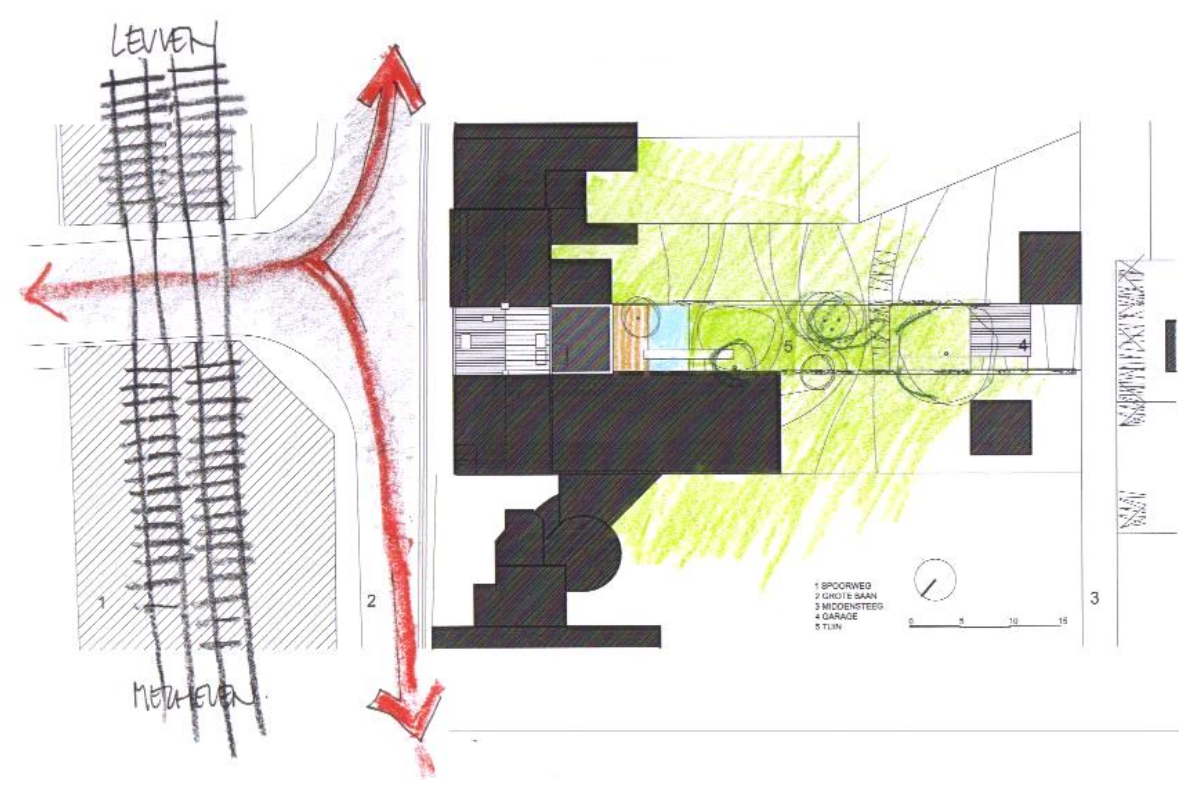

Fig. 5 Implantation plan.

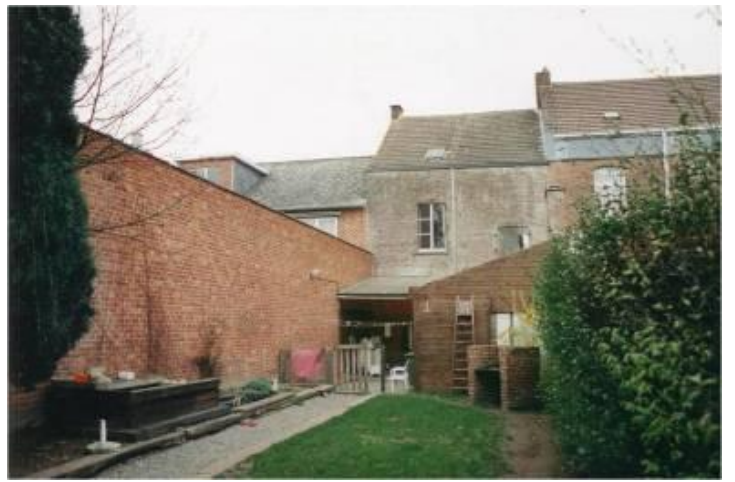

Fig. 6 Existing situation seen from the garden.

\subsection{Designing process}

During the creative process for the renovation itself, Verplancke didn't have a critical client, a non-architect as a "partner" in the different stages of the design. He had to be his own reviewer. And he saw himself approaching such a task through his experience as a painter. Spontaneously he made several paintings as a way to complete his "reading" of the existing space in terms of atmosphere, authenticity and opportunities.

A first painting (Fig. 7.1) depicts the front façade as a composition of surfaces, lines, forms and colors, cleaned up and reduced to the essentials just by removing the traditional window partitions. It shows the façade as a two-dimensional surface. The second painting (Fig. 7.2) shows the middle wall between the front and back living space with a combination of existing and new openings, it shows an intention to create more relations in between spaces in the basic volume of the row house. The third one (Fig. 7.3) shows the former back façade of the existing volume. New "openings/windows" are positioned in order to create relations between the inside of the volume and the garden in the back. Colors are used to define surfaces guiding the flow of space between the old and the new. The right wall (red surface) is sliding into the expanded opening towards the staircase. In this painting the third dimension appears. The last painting (Fig. 7.4) shows an impression of the new back façade, a blown up square linked to the square-formed windows in the front façade and to the yellow living room of the second painting. The height is also linked to the red brick wall of the old warehouse next door.

The four paintings can be seen as four vertical layers moved "into" and behind the existing volume, the different colors shows the relations to be created. In parallel with these paintings the "regular" reading of the existing; both in plan and section; gave birth to the final concept: to change the orientation of the living area from the once quiet street towards the garden. He kept the volume of the existing row house, demolished the annex in order to create space for a new living-box facing the garden. The existing plan didn't use the full width of the ground. By removing the annex and moving the "serving"- functions, kitchen, bathroom, 

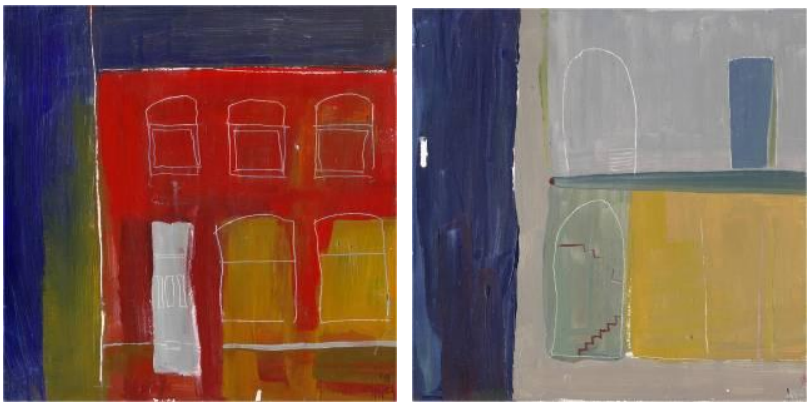

Fig. 7.2 middle wall;

Fig. 7.1 front façade;
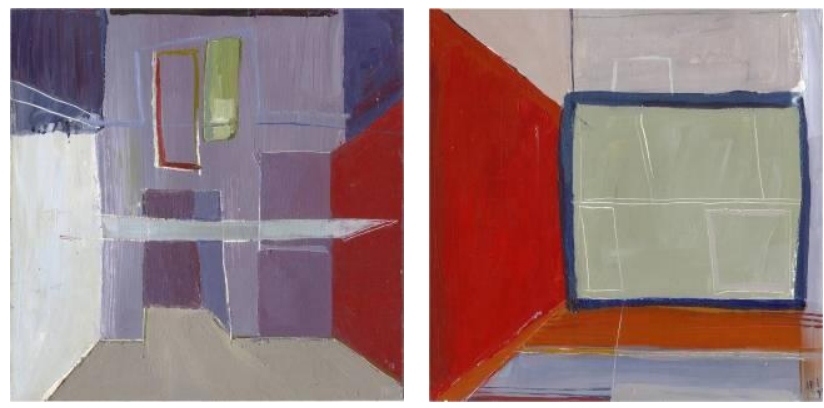

Fig. 7.3 formal back façade; Fig. 7.4 new back façade.

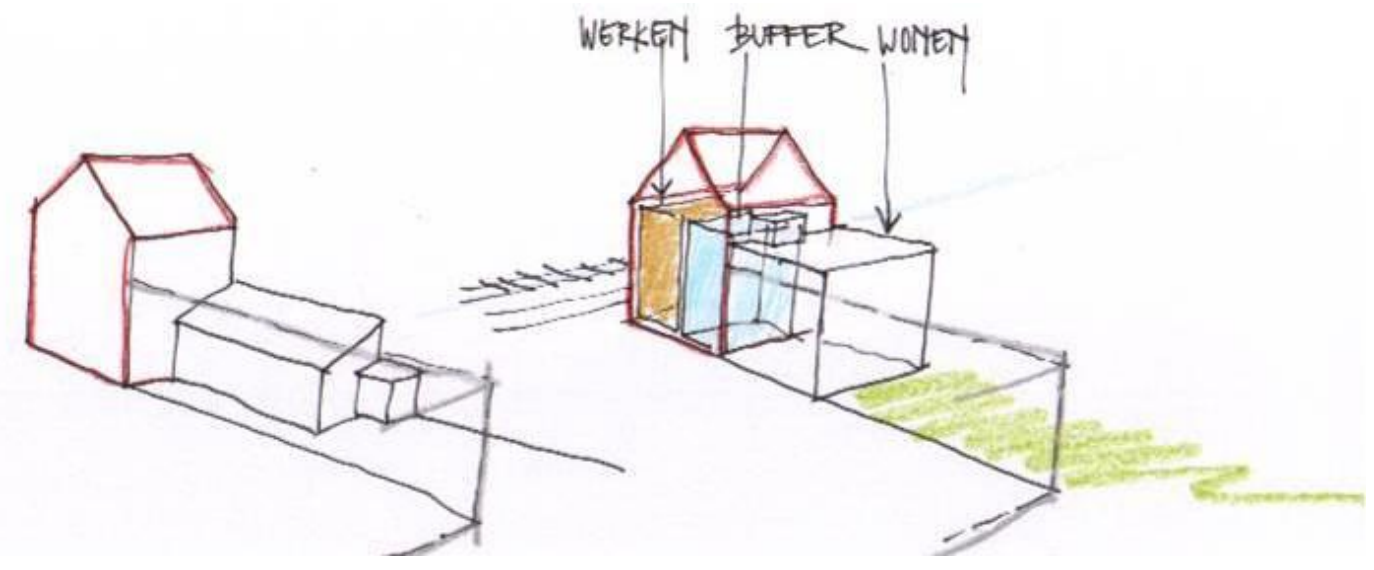

Fig. 8. basic volumetric concept.

scullery and archive towards the middle of the new global volume (Fig. 8) he could create a new double high space containing the family-room.

The existing rooms in front would contain, on the ground floor, the dining room (also used for meetings with clients), on the first floor the architect's office. Working space was thus positioned in relation with the more urban part of the site. The "functional" zone was conceived as an acoustic barrier for the noise of the railway and the new traffic in front.

That concept was realized both in plan and section (Fig. 9), focusing on one hand on the possibility of capturing sunlight all year long, on the other hand on the creation of a visual connection between street and garden through the house itself.
The proportions of the new backside box are the same as the main living room in front, a way to "connect" that new living space to the existing volume. The bigger width and height, the glazed façade and a sky light positioned in the connection between new and old, made it possible for sunlight to penetrate into the basic volume of the house. The bigger height opens the view towards the deep garden in the back.

Finally it had to be an "open" house, a house in which the different functions were part of a new spatial concept without doors to separate functions, only using the varying dimensions of the different rooms to define them. Fig. 10 shows the final plan for the reconversion of the house. 


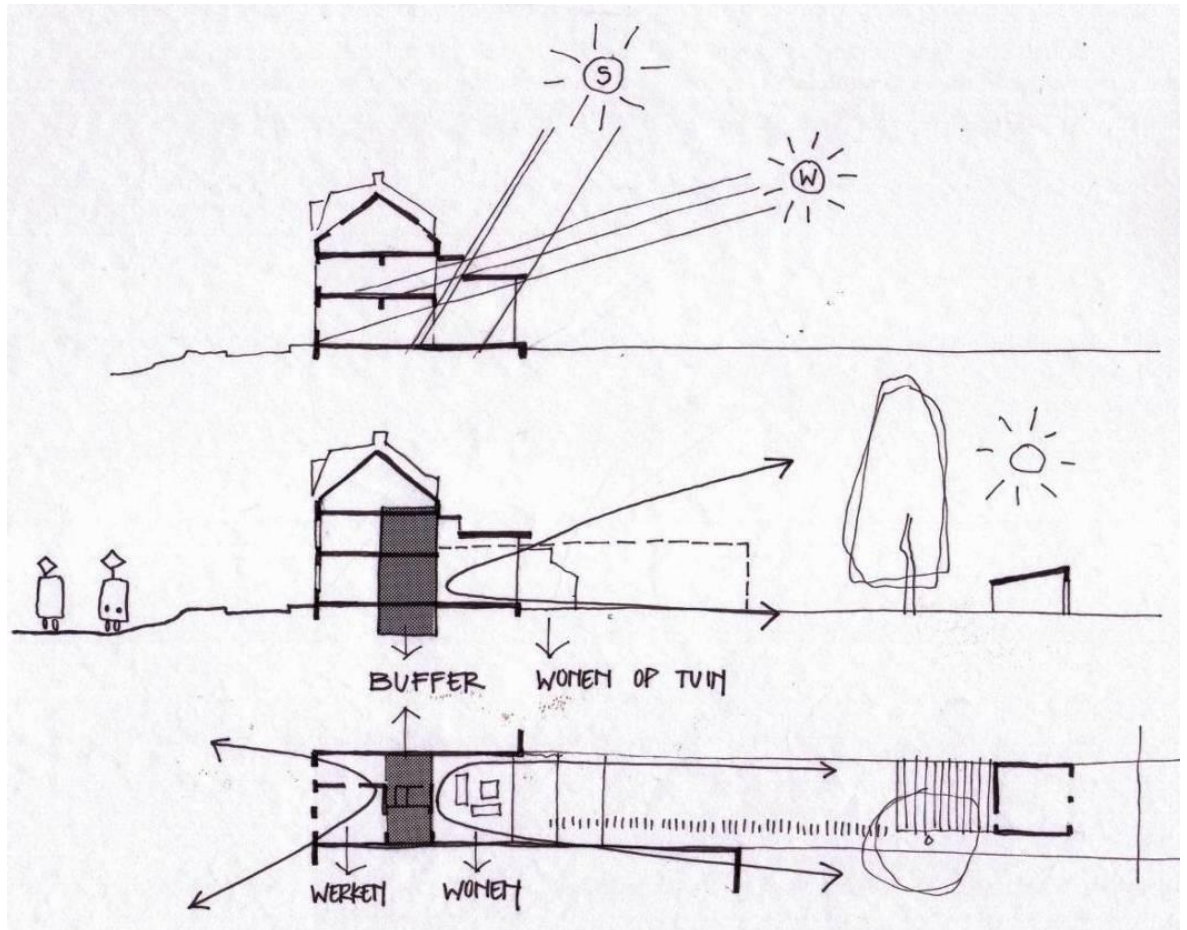

Fig. 9 concept in plan and section.

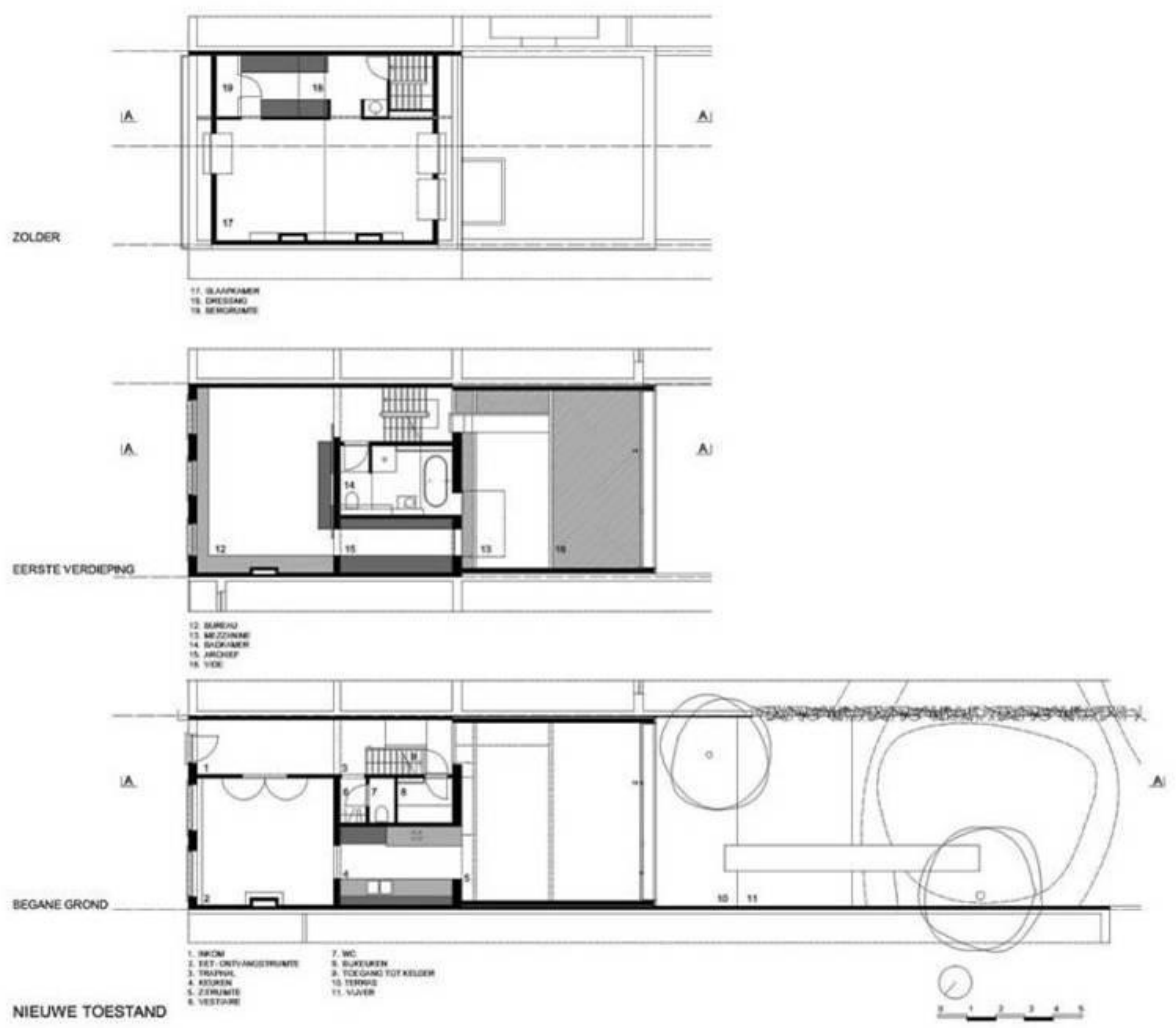

Fig. 10 plan new situation. 
On the ground floor, the new kitchen (Fig. 10.1) connects the dining room with the living space. On the first floor the archive realized a see-through from the office in front to the double high living space and garden in the back (Fig. 10.2). The mezzanine hanging in the new living box is an in-between space putting the new transparency of the whole in evidence (Fig. 10.3). From here there is a visual connection with living room, kitchen, dining room, office, bathroom and garden. The once "closed" staircase is opened towards the new living space and garden (Fig. 10.4).

Gradually the rear extension grew into a white cube surrounded by a sharp frame in the back. No overdesigned stairs and railings, no continuous walls and floors. The house was pure. The steel frame is structure and form. It hides roof edges, rainwater pipes, solar screens and it amplifies the idea that the new living room was simply slid between the existing common walls. The large glass wall in the rear façade has a simple partition. The different colour of the sliding windows (Fig. 11.1) is almost the only 'frivolous' element in its design, but this was also a deliberate choice to maintain a constant width in the fixed frames and to make difference clear between the open and the closed position of the window. The position of the only structural element (the steel column) gives from the inside the impression of a completely glazed surface in the middle of the façade. (Fig. 11.2)

Through the large glass wall the living smoothly extends into the garden, without needing continuous walls or floor levels. The garden has a completely different design, which is an important plus value [9].

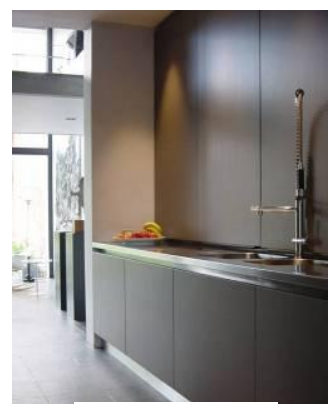

Fig. 10.1

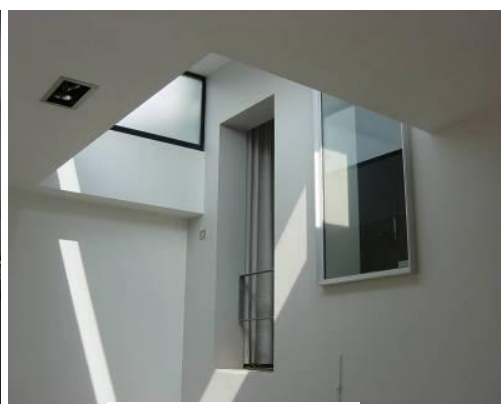

Fig. 10.2

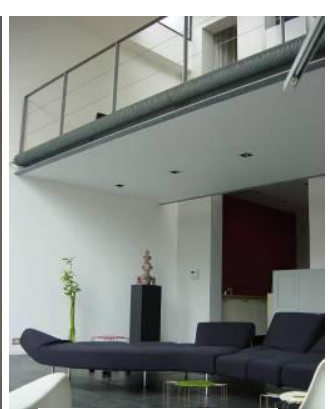

Fig. 10.3

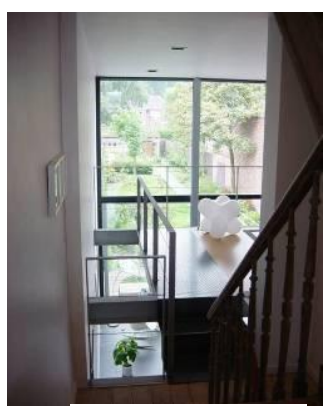

Fig. 10.4

Fig. 10. : 1. view into the kitchen; 2. detail of the skylight in the new extension; 3. new extension with mezzanine; 4. existing staircase opened to the new extension.

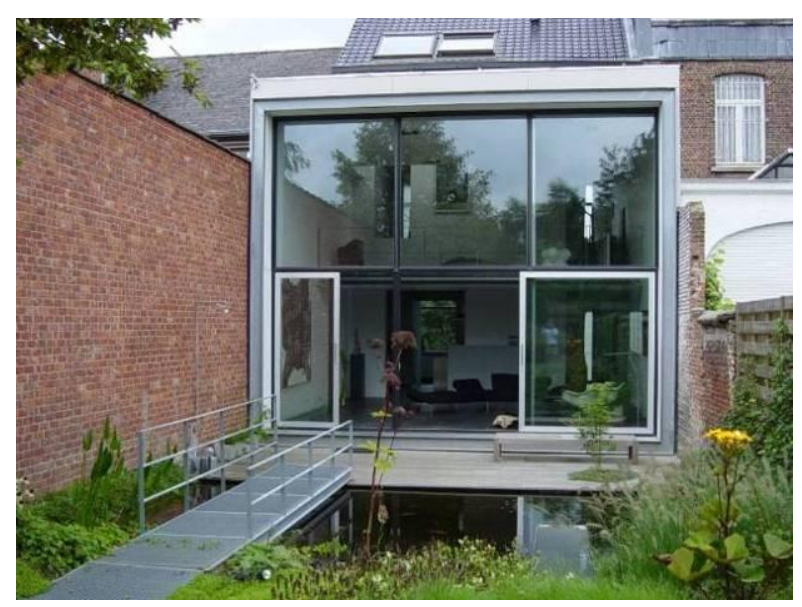

Fig. 11.1. view to the new back façade.

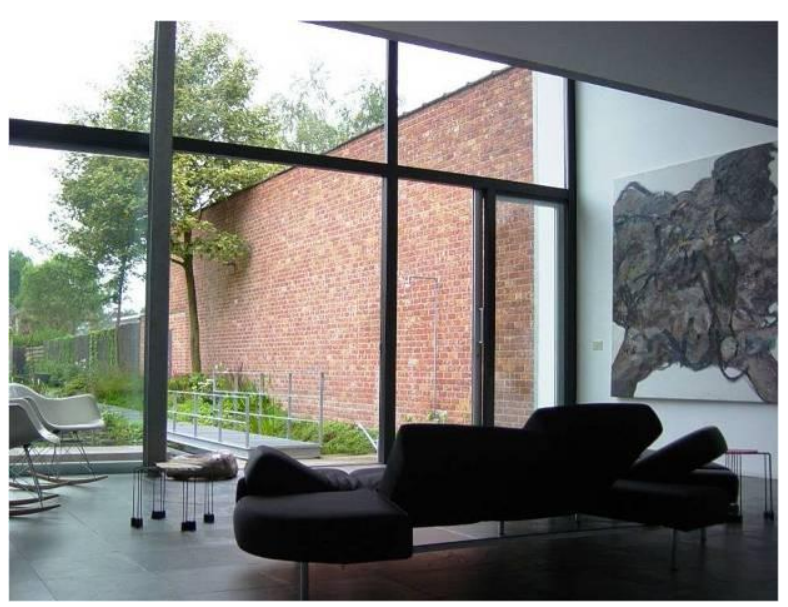

Fig. 11.2. view into the garden. 
This house realizes 'literal transparency' in many ways. On a first level, the back façade is literally transparent, providing a clear visibility and a smooth transition between exterior and interior space. Likewise, the front façade, although offering less see-through surfaces, is not ambiguous: the fact that a first layer of 'professional' spaces is to be found immediately behind this wall is easily notable. The big service-volume in the core of the house provides a screen that clearly delineates the 'professional' volume. The spatial interpretation is thus clear. On a more complex level, there is also a form of literal transparency between the paintings and the final design for the reconverted house. The paintings visualized a certain interpretative 'mapping' of the house, which then was - quite literally we would argue - translated into a new spatial concept.
It doesn't require a lot of imagination to go from the paintings towards the final design, and the 'translation' does not imply ambiguities or uncertainties.

\subsection{Second house}

After 10 years it was time for a new project. Not a reconversion of an existing house but a project from scratch. Verplancke found a building site in a recent development. It was the only parcel not being sold immediately. The somewhat awkward position of the parcel into the whole explains why.

3.3.1 Freestanding house. From the beginning, similar with the row house, the relation with the context had to be taken into account. The building plot was situated in the "corner" of the development, hidden behind the already constructed neighbors (Fig. 12).

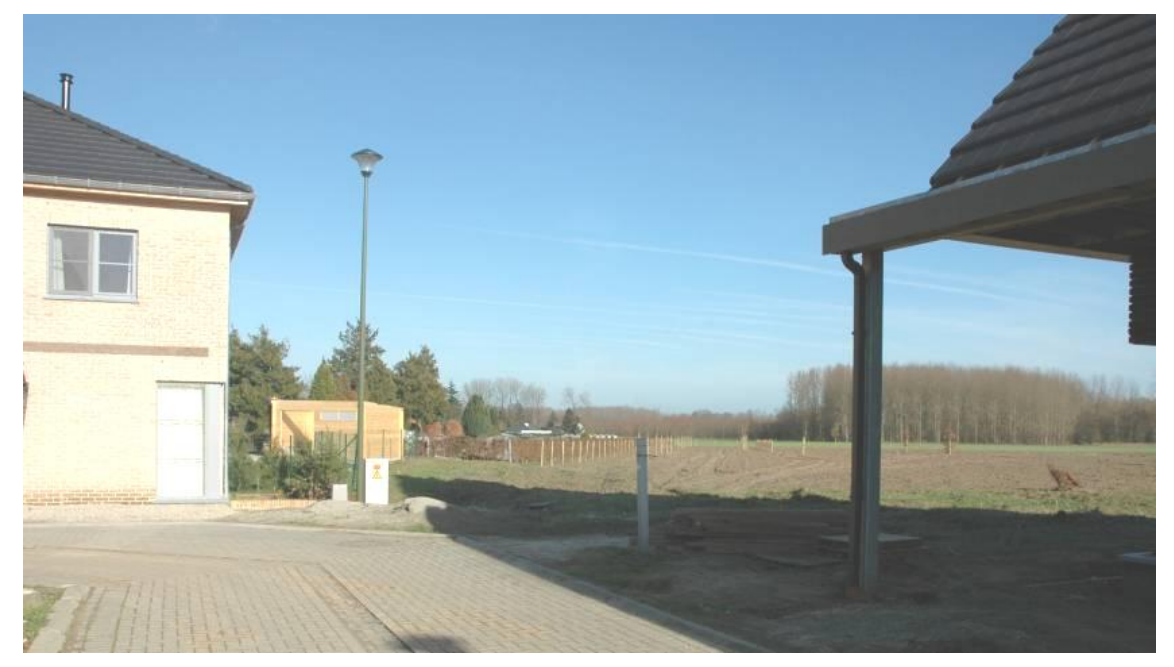

Fig. 12. building plot, existing situation.

The building site, almost 1 ha big, bordered on six meter on the street in front, had on the longest side the cemetery of the village as neighbor but looked out over a wide landscape, partially a protected nature reserve.

3.3.2 Design process. In front of constraints and potentials of the building plot, this time he approached the project from his experience as a sculptor. Therefore the designing process started with the conception of a volume, a sculptured mass closing the corner in between the existing neighbors (the approach starting from a sculptured mass is close to that of other designers such as e.g. Rick Joy) [10]. Regulations asked for a rectangular plan with a maximum surface of $180 \mathrm{~m}^{2}$. That configuration (Fig. 13.1) restricted a view into the depth of the garden. Verplancke started by changing that contour into a polygon with the same footprint but opening to the landscape (Fig. 13.2).

Although a building with a flat roof was allowed, he chose to give the volume partially a slope towards the landscape. The result was one strong volume with openings where a relation to the landscape was desirable. A big glazed façade looking to the landscape, a north orientated window showing the angle (Fig. 14.1) and a large cut-out at the entrance providing space for a carport. (Fig. 14.2).

Into that "envelope" he created a sequence of both open and intimate space, looking for specific proportions in plan and section. He wanted to create a continuous space, but every functional zone had to have an own atmosphere in the whole. (Figs. 15.1/2/3) 


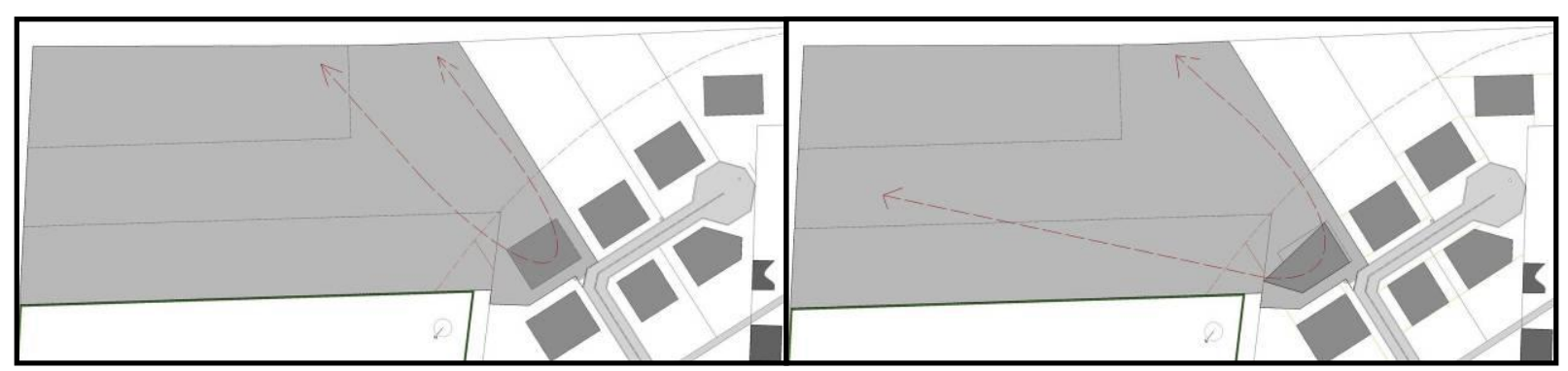

Fig. 13.1. implantation according to regulations

Fig. 13.2. proposal for new footprint.
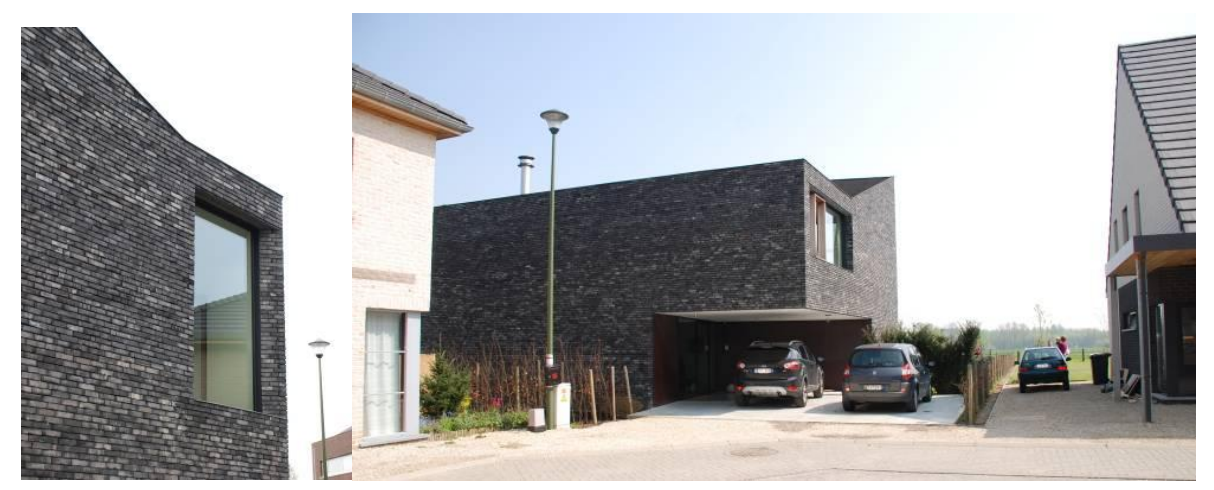

Fig. 14.1. void-window, meeting point of plan directions (left); Fig. 14.2. carport as extension to the street (right).

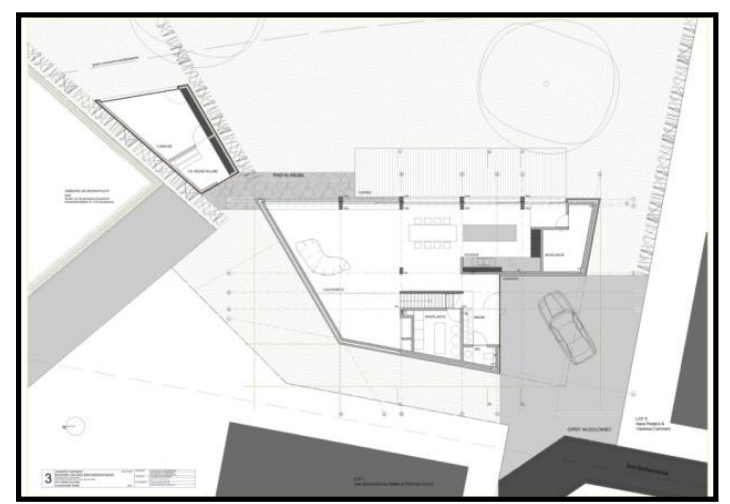

Fig. 15.1 first floor ;

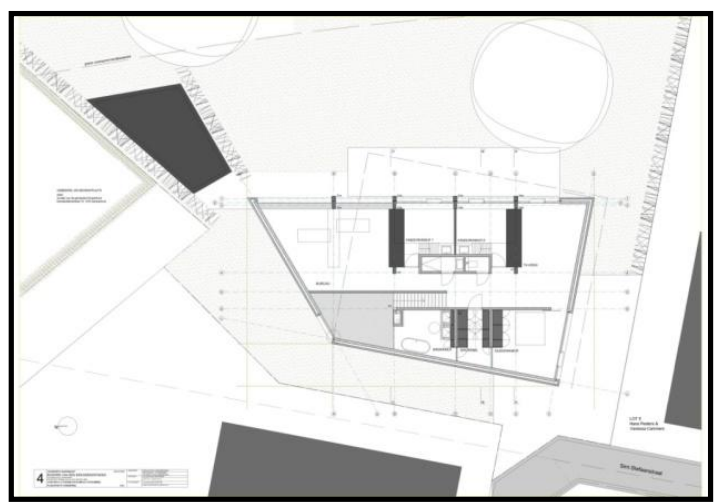

Fig. 15.2 second floor.

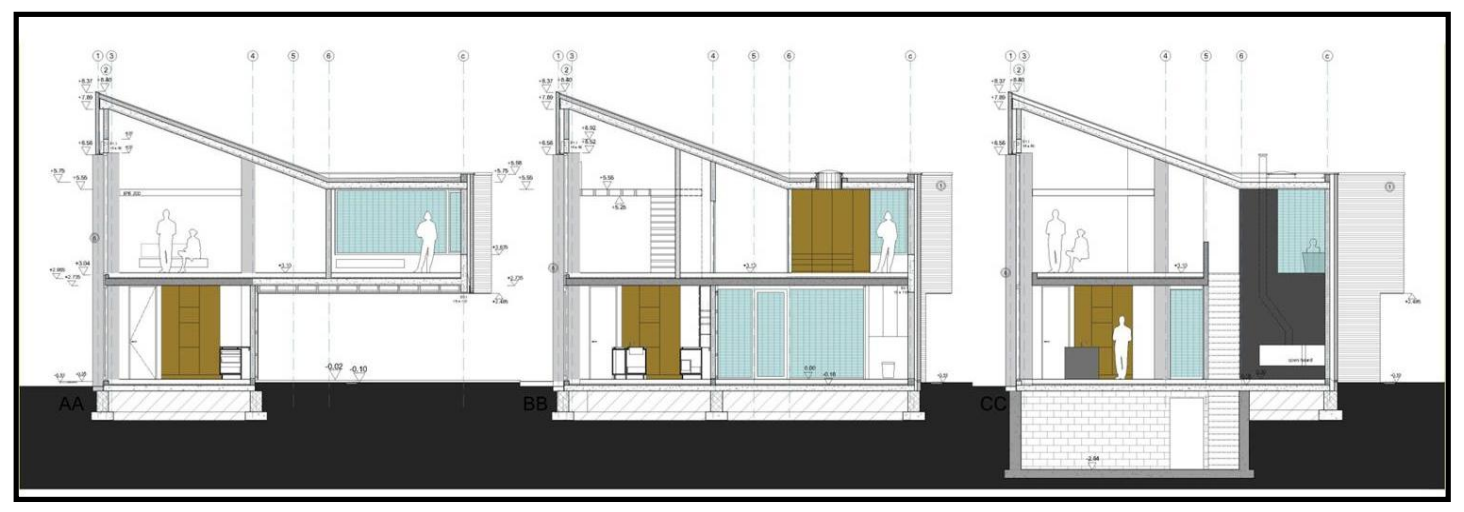

Fig. 15.3 sections. 
Living room, dining room and kitchen were located in the length of the garden; functional spaces were located as ending and in-between volumes. The double high fire place is the most intimate part of the living area, implementing a transition to the second floor. (Fig. 16)

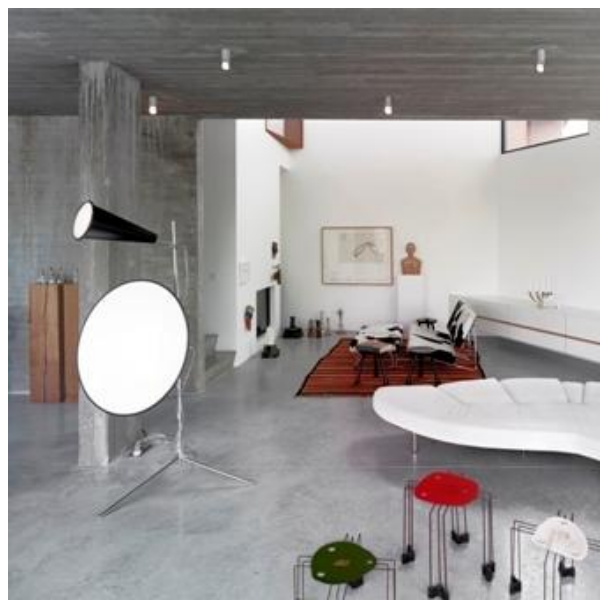

Fig. 16. living room and double high fireplace.

The second floor is divided in a zone at the street side with master bedroom, dressing and bathroom. The back side remained an open space that could be divided in separate rooms when necessary. When entering the house it feels like entering a continuous space, a cavity with ever new dimensions. There is no such thing as a formal entrance, a circulation zone or corridor. On the second floor the circulation zone coincides with library (Fig. 17) and atelier. The final construction grid is both visible and not visible in the interior.

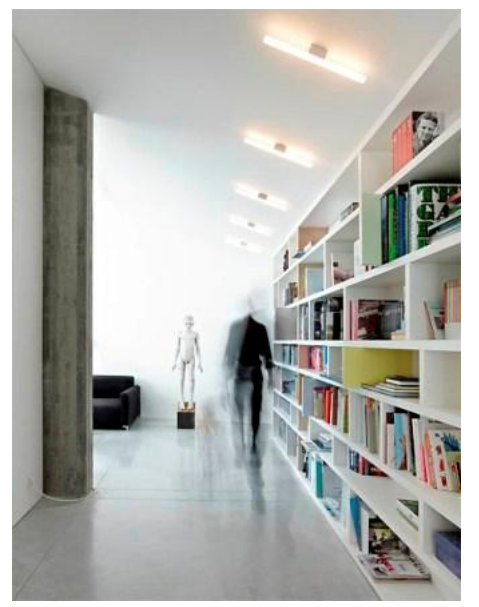

Fig. 17. circulation zone is more than a corridor.
The wide view over the landscape is indeed part of the main living spaces. This is achieved while blocking at the same time the view from the cemetery towards the inside living area. (Figs. 18.1/2). The main material for the structural elements is concrete - rough, wood-nerved and solid. All floors are in polished concrete, divided in "fields" following the grid. The constructive grid is linked to the desired views - no beams blocking the view to the sky. (Fig. 18.3)

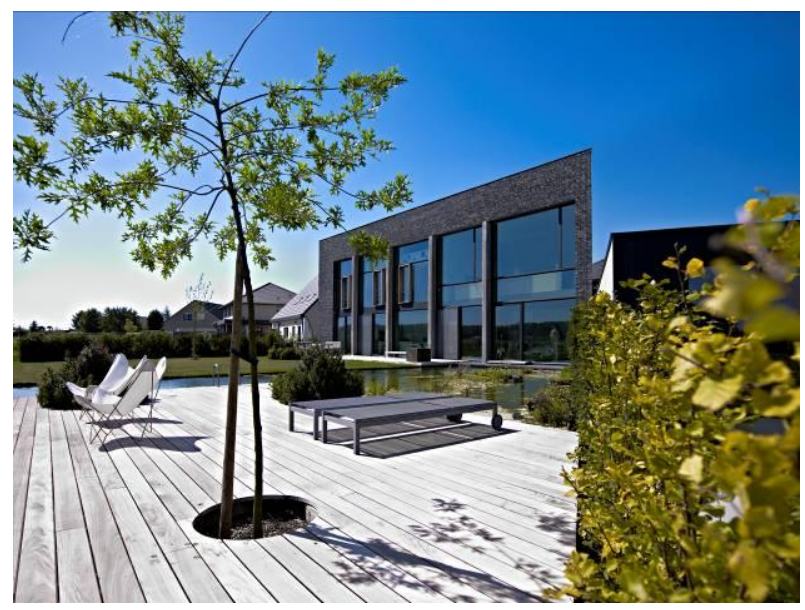

Fig. 18.1. view from the terrace.

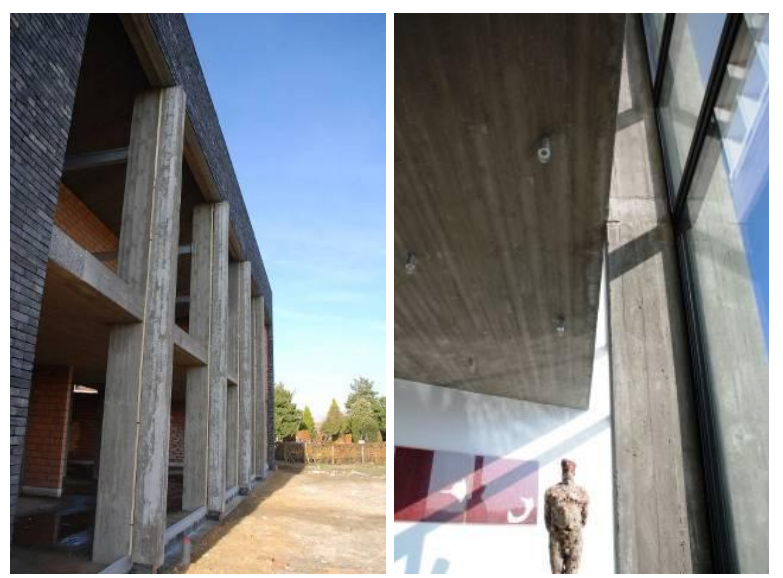

Fig. 18.2. concrete structure on a grid (left); Fig. 18.3. detail of structure (right).

For the materialization of the project contextual elements were decisive. The brick walls echo with rough blue-grey color the graves of the nearby cemetery. Walking there, the house offers a quasi-solid sight, with the near window-less North East façade and the opaque windows of the garden façade (opaque in this case because of the oblique angle under which they are perceived). (Fig. 19) 


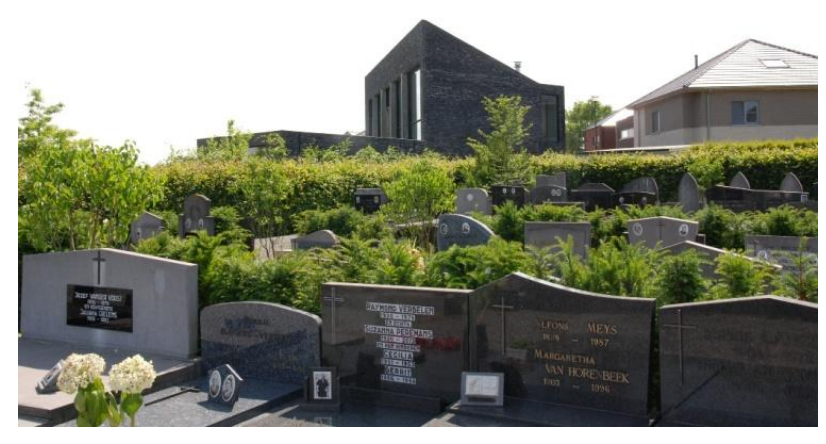

Fig. 19. view from the cemetery.

Wood is used for window elements marking a relation to both inside and outside. The wooden "balconies" in the East and South façade are both aesthetic (giving proportion to the big surfaces) and functional. They provide "openings" in the children's rooms, the TV-corner and the master bedroom. A similar wooden window was used for the interior window between bathroom and the void above the living room - the position and form referring to the regulatory construction grid (Figs. 20.1/2).

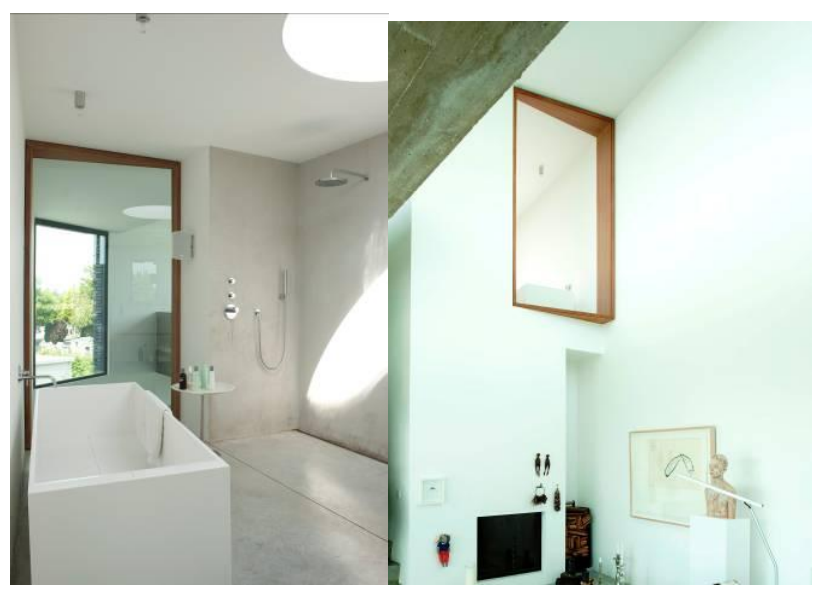

Fig. 20.1. view from the bathroom towards void and cemetery (left); Fig. 20.2. view into the void (right).

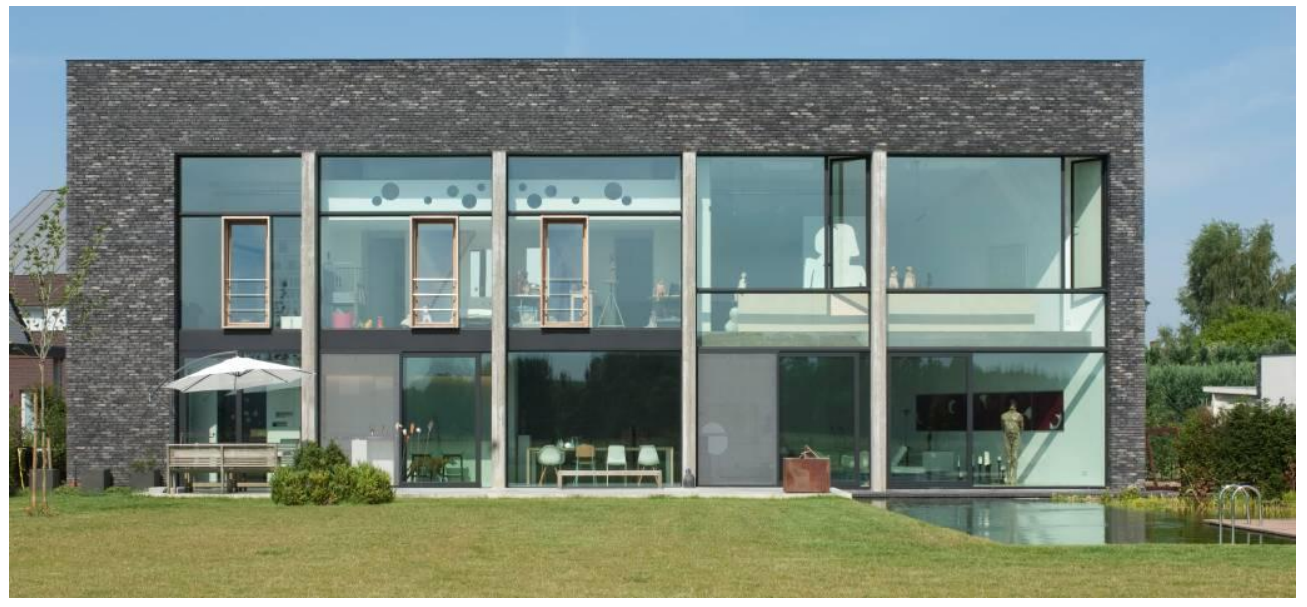

Fig. 21. back façade.

The back façade (Fig. 21) offers a clue to better understand how Verplancke dealt with the interaction between inside and outside. The façade is more than a simple glass wall, because the glass is punctuated by different elements: slightly irregular structural columns subdivide it vertically, whereas a horizontal subdivision sometimes coincides with a floor behind it (kitchen), sometimes only reminds one of an absent floor. Places where the view to the sky or garden had to be kept open like the living room and the atelier or sometimes simply providing a supplementary surface regulating the view (balustrade in children's rooms) (Fig. 22).

Although the volume of the house appears as a massive block, once you enter the house, none of the living spaces is a closed or geometric form. The design of the rooms inside the envelope can be seen as floating space enlightened by sunlight all day long. 


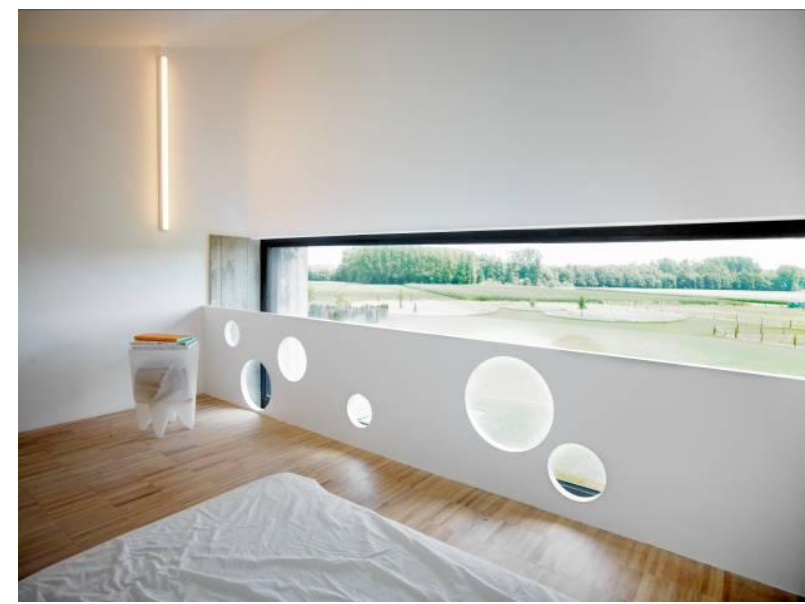

Fig. 22. view from mezzanine children's room.

This house realizes, rather than literal transparency, phenomenal transparency. Especially the glazed garden façade provides a multilayered space that can be interpreted in different ways: as a simple screen between inside and outside, as a shallow space allowing for the interplay between constructive elements (columns, beams, floors) that protract and recede from the plane delineating interior from exterior, as a visual mechanism inviting views towards the garden while blocking views from the cemetery, as a buffer space that suggests shallow, deep and very deep interior spaces, without however making it completely clear which space is how deep exactly. This ambiguity, it seems to us, is what Rowe and Slutzky describe as phenomenal transparency. That transparency also comes forth from the remarkable sculptural gestures one recognizes in this house. The final volume results, as it were, from a complex sculptural process, in which a given geometry was carved out, slightly modified and given an appropriate finish to answer contextual appeals ranging from functional ones (carport), over emotionally charged ones (the relation with the cemetery) to visual ones (the presence of the sky). The house reacts mimetically to these multiple factors, folding them into one another in such a way that the resulting object can be read in many different ways, but always in relation to its context.

André Loeckx once described a house by Marie-José Van Hee, another Flemish architect, as a "third house" positing the 'manifesto' and the 'metaphor' as first and second. With the 'manifesto' house referring to iconic designs by famous architects whereas the 'metaphor' points towards Walter Benjamin's idea of a house that would enclose its inhabitant as a compass case, 'where the instrument with all its accessories lies embedded in deep, usually violet folds of velvet' [11]. In terms of our discussion, the Farnsworth House by Mies Van der Rohe could be seen as the 'manifesto' of literal transparency, whereas the Stoclet House by Josef Hoffmann is a very good example of a 'metaphor' house. In both these types of houses, Loeckx argues, there is no elbow room for the inhabitant: in the 'manifesto' house the inhabitant is negated because the architect's authorship takes precedence, [12] in the 'metaphor' house, the Gesamtkunstwerk approach of the architect threatens to barely leave room for the inhabitants to appropriate the house as their home. Loeckx's 'third house' brings together context, dwelling's conception and designing process into a work that combines the authorship of the architect with the potential of appropriation by inhabitants. Marie-José Van Hee, he argues, "gives priority to seeking a timeless dimension. In order to rediscover the essential joys of life that we have lost, she pursues sensuality in her work, rather than adopting a purist or ascetic attitude" [13]. Such an architect doesn't start a design with pre-defined models, rules, typologies and well known cases in order to repeat them but he/she approaches the design as a new task where the decisions are generated in response to the context. Hans Verplancke, we argue here, also produces this type of 'third house', using phenomenal transparency to respond to contextual elements while at the same time providing room for the insertion of the inhabitants (in this case: himself and his family) into the interstices resulting from the complex design process. This kind of architecture indeed produces indelible spatial sensations (openness and enclosure, transition and separation, connection and division), while at the same time receiving daily life in a non predictable evolution.

\section{Conclusion}

Building up a freestanding family house fits into the Belgian home culture: people want a house of their own to shelter their family in a micro-cosmos that performs a lifestyle in contact with nature. This can be seen "in the choice of locations but also in the fact that terraces, gardens and courtyards took an important part of our daily life and living culture" [14]. Hans Verplancke's designs for both his own houses should be considered within that tradition. The first house realizes this dream of contact with nature, in a somewhat stifling context with a lot of noise pollution, by radically opting for an architectural gesture that disrupts the flow from front to back by inserting a closed service-volume in the middle of the house, thus performing literal transparency in both front and back sides of the house. The second house, which is set into semi-rural context, goes a step further in its interaction with the complex context that consists of a suburban-like street on the one hand but also a 
cemetery and open landscape on the other. By means of 'phenomenal transparency' this house negotiates this context in a marvellous way, opening up and closing off, interacting with its context while at the same time turning its back to certain parts of it. It thus seems that the analytical tool that Rowe and Slutzky proposed so many years ago, can still help us to unravel and better understand what is going on in an intricate design process. The major difference with the sixties - we would argue - is to be found in the fact that in the case of Hans Verplancke (like in that of Marie-José Van Hee) both literal and phenomenal transparency are not formal devices for their own sake but that they are thoroughly informed by the contextual elements.

\section{References}

[1] Kristiaan Boret, 'Verdichting met mate. Verbouwen van een rijwoning, Wespelaar' in Jaarboek Architectuur Vlaanderen 00 01, Ministerie van de Vlaamse Gemeenschap, 2002, 102-103

[2] Sigfried Giedion, Space, Time and Architecture. The Growth of a New Tradition, (1941), Cambridge: Harvard University Press, 1980

[3] Colin Rowe and Robert Slutzky, "Transparency. Literal and Phenomenal" (1963), in Colin Rowe, The Mathematics of the Ideal Villa and Other Essays, MIT Press, 1990, pp. 159-184

[4] Colin Rowe, 1990, 168

[5] Colin Rowe, 1990, 171

[6] Colin Rowe, 1990, 175

[7] Colin Rowe, 1990, 175

[8] Colin Rowe, 1990, 160
[9] Content from Hans Verplancke's interview given to Oana Bogdan in Architectura, 13 serie noua (octombrie-noiembrie/2002), 111

[10] Steven Holl and Juhani Pallasmaa, Rick Joy Desert Works, New York, Princeton Architectural Press, 2002, 65

[11] André Loeckx, William Mann and Kristiaan Borret, Marie-José Van Hee Architect, Gent-Amsterdam Ludion 2002. The reference to Walter Benjamin is to Walter Benjamin, The Arcades Project, Harvard University Press, 1999, p. 200. A text by André Loeckx in English on the architecture of Marie-José Van Hee can be found in: André Loeckx, 'Mediating Houses: Marie-José Van Hee's domestic architecture', in Hilde Heynen \& Gülsüm Baydar (eds), Negotiating Domesticity. Spatial Productions of Gender in Modern Architecture, Routledge, 2005, pp. 252-280

[12] For the Farnsworh House, see Alice T. Friedman, 'Domestic Differences: Edith Farnsworth, Mies van der Rohe, and the General Body' in Christopher Reed (ed) Not at Home. The suppression of domesticity in modern Art and Architecture, London, Thames \& Hudson, 1996; for the Stoclet House see Peter Noever a.o., Yearning for beauty: the Wiener Werkstätte and the Stoclet House, Vienna: Mak, 2006.

[13] Gennaro Pstiglione [ed.], One hundred houses for one hundred architects, Köln, Taschen, 2004, 412

[14] Karina Van Herck, 'Huizen met eigenschappen. De individuele woning als plaats van geluk en zelfrealisatie' in Jaarboek Architectuur Vlaanderen 04 05, Vlaams Architectuurinstituut, 2006, 41. 